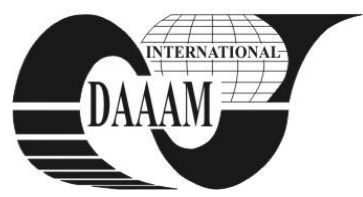

Annals of DAAAM for 2011 \& Proceedings of the 22nd International DAAAM Symposium, Volume 22, No. 1, ISSN 1726-9679 ISBN 978-3-901509-83-4, Editor B. Katalinic, Published by DAAAM International, Vienna, Austria, EU, 2011 Make Harmony between Technology and Nature, and Your Mind will Fly Free as a Bird Annals \& Proceedings of DAAAM International 2011

\title{
CREEP BEHAVIOUR OF THERMOPLASTICS CROSSLINKED BY IRRADIATION
}

\author{
REZNICEK, M[artin]; CERNY, J[akub] \& PATA, V[ladimir]
}

\begin{abstract}
Investigation of mechanical properties of polymer materials is today part of ranks of studies, but which by their nature, mainly for reasons of time, ranks among the short-term tests. The article summarizes the basic requirements they have to implement the measuring device and on the basis of these requirements demonstrates the actual construction of the measuring equipmen at the Institute of Production Engineering develops and trials. (Stanek et al., 2009)
\end{abstract}

Key words: phenomenon of creep, creep, measuring, construction

\section{INTRODUCTION}

Polymer materials are common part of everyday life, but they are more prone to creep compared to other materials and so it is necessary to measure and study them. But as the tests are very time-demanding and money consuming, this area still lacks sufficient research. Hence a simple measuring device was designed and made to test four specimens at ambient temperature. The measuring device will be further developed to enable creep tests at higher temperature. (Dobrescu et al., 2009)

Measurement of material creep is performed according to the international standard ČSN EN ISO 899-1, Plastics Determination of creep behaviour. Specimens are the same as those used for tensile tests of polymer materials. The device used during the test should meet a number of requirements which are given by the above standard. Among the requirements which the device must meet are constant load of the cross section in the direction of the axis of the specimen in order to achieve single-axle tension. The specimen must be conditioned to balance temperature and humidity of the specimen which can influence the results of measurements. In the course of the test it is necessary to ensure constant temperature and humidity which must also be monitored. (Stanek et al., 2006)

\section{EXPERIMENT}

A number of problems occurred during the construction of the device that required solution. It was necessary to ensure sufficient total rigidity so the results were not influenced by deformation of the construction. The values of elongation were measured by dial measuring gauge with definition of $0,01 \mathrm{~mm}$ and range of $12,7 \mathrm{~mm}$. The communication was performed via a conversion device to the serial port. The whole measuring device was placed in a laboratory with no-one allowed to enter. This ensured constant temperature and humidity. Thanks to its suitable placement in the room it was ensured that the measurements results were not destroyed by an interference of a person during the measurement. (Brnic, 2010)

These requirements were used as the basis for designing and manufacturing a measuring device to measure the creep properties of polymer materials. This measuring device is designed to measure small specimens according to the standard $\breve{C S N}$ EN ISO 527-2. They are fixed by wrists whose shape is adjusted to the specimens for better fixture. Load is applied to the specimens using lever mechanism at the ratio of 1:5 and $1: 10$. The arrangement of the four specimens is done in such a way to enable to place weights on the levers up to $20 \mathrm{~kg}$ and by this apply load on the specimens from $25 \mathrm{~N}$ to $1960 \mathrm{~N}$. The total construction is modular, with the weight is placed in the bottom piece to eliminate vibrations during measurements. The top smaller part is removable to enable its future placement in the temperature room. The values of elongation are read by the dial measuring gauge with data output into the computer, in which there is a single use programme which records the values.

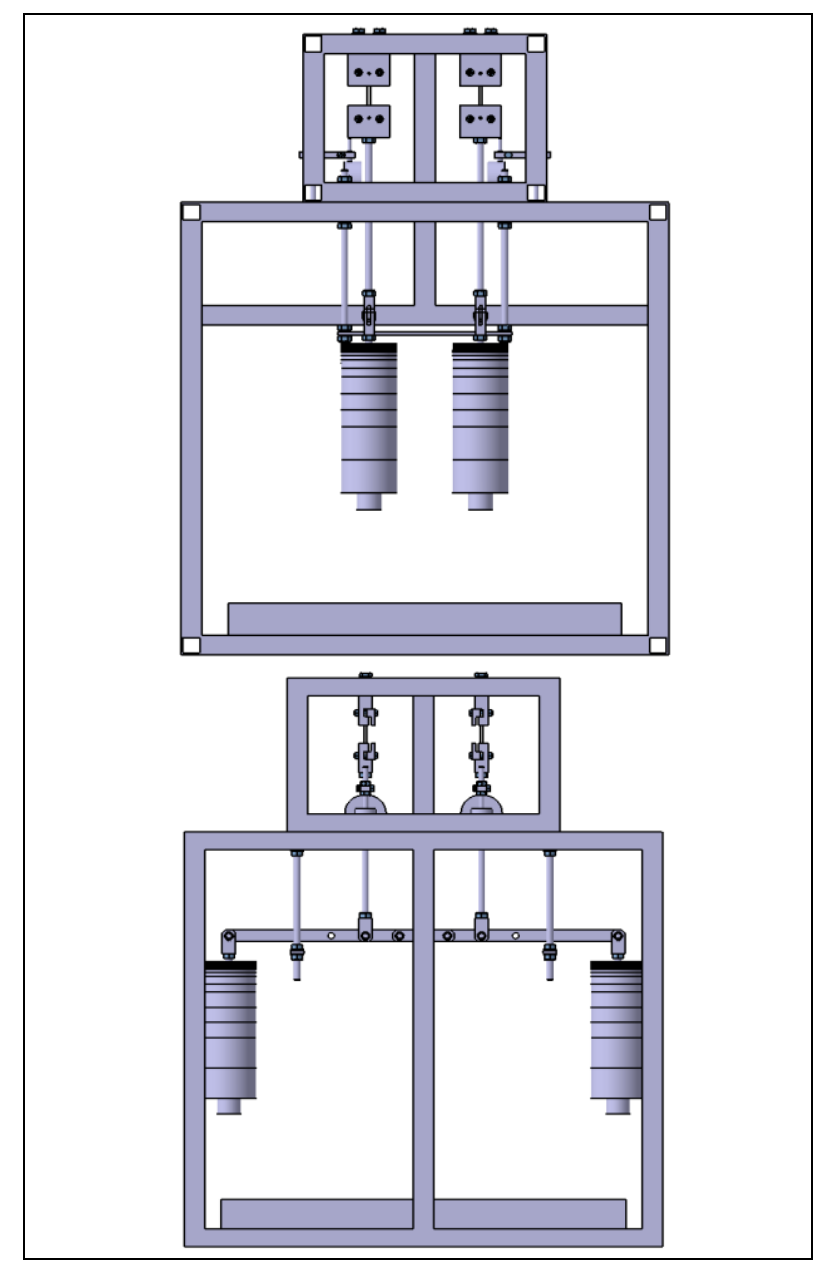

Fig. 1. Implementation of design in the CAD software Catia V5R18

The experimental measurements to find out the influence of radiation cross-linking on the mechanical properties of polymer materials verified its trouble-free operation and important influence of this radiation on creep properties. The load applied to the specimen injected from PA1 $1+25 \%$ GK was, in all the 
measured cases, 14,7 MPa in the axis of the specimen. The reading interval was 60 seconds and the length of measurement was 100 hours. (Stanek et al., 2009)

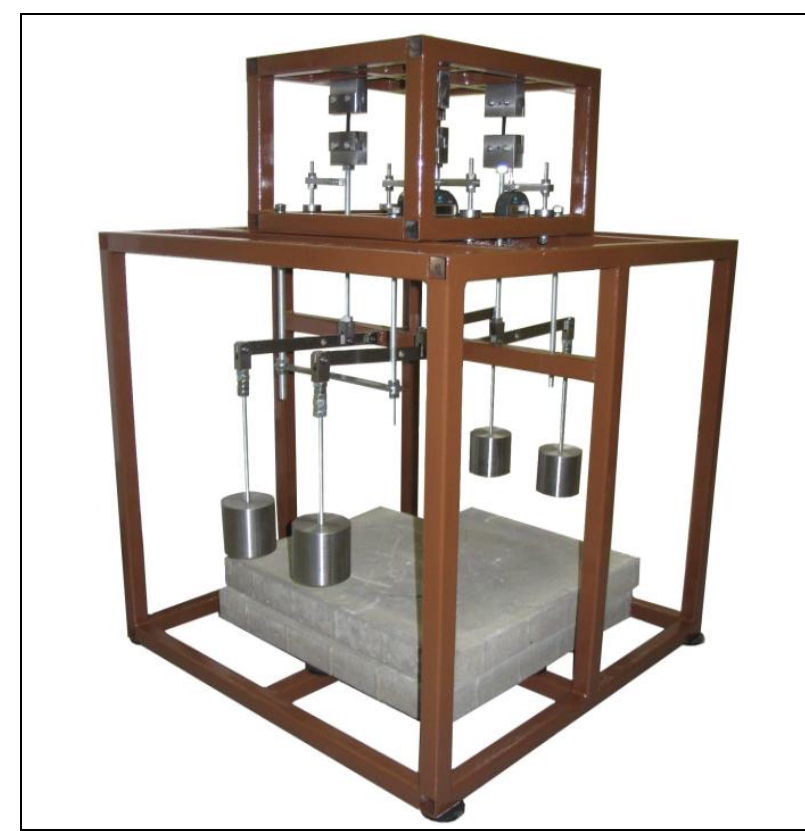

Fig. 2. Implementation of the measuring device

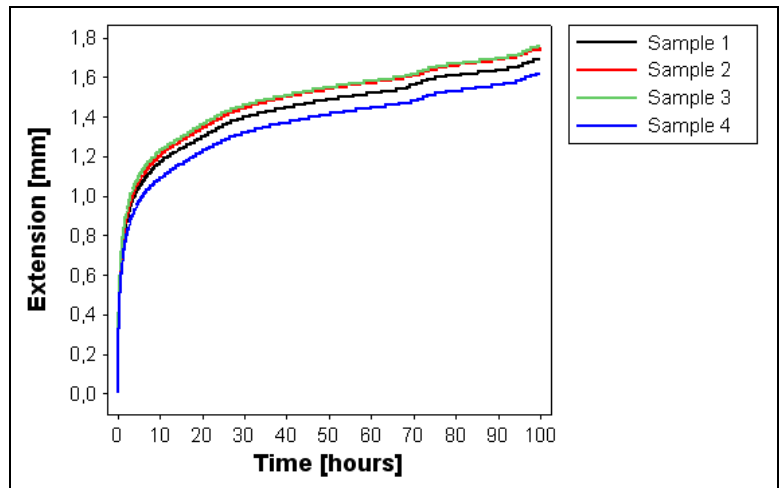

Fig. 3. Elongation PA11+25\%GK, 0kGy

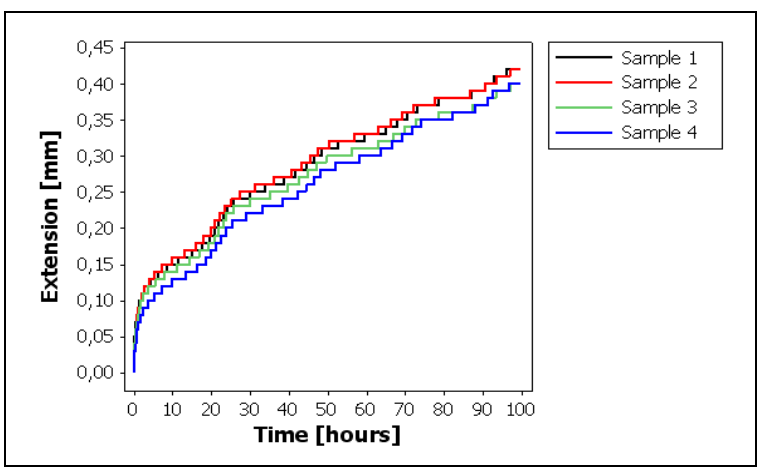

Fig. 4. Elongation PA6, 0kGy

\section{CONCLUSION}

The results of the measurement confirmed that the construction was well designed. Deficiencies were found in the dial measuring gauge which is not able to properly monitor the changes when the elongation is small. This reason will lead to replacement of these gauges for a more accurate one, there will be more tested specimens and a temperature room enabling to observe creep at higher temperatures.

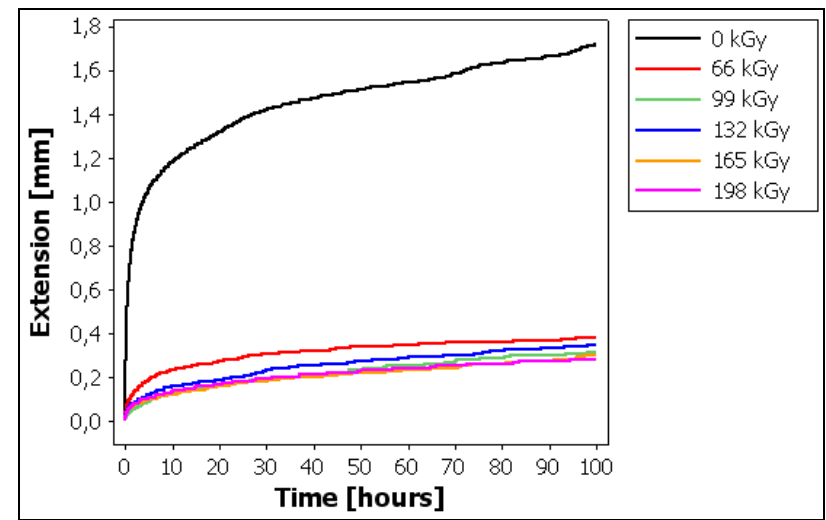

Fig. 5. The influence of radiation dose on phenomenon of creep properties

\section{ACKNOWLEDGEMENTS}

This article is supported by the internal grant of TBU in Zlín No. IGA/10/FT/11/D funded from the resources of specific university research.

\section{REFERENCES}

Brnic, J. (2010). Properties Comparison of Two Constructural Steels: ASTM A709 and ASTM A505, DAAAM Symposium, 20-23rd October 2010, Zadar, Croatia, ISSN 1726-9679, ISBN 978-3-901509-73-5, Katalinic, B. (Ed.), pp. 0085-0086, DAAAM International Vienna, Vienna

Dobrescu, T.; Enciu, G. \& Nicolescu, A. (2009). Selection of Process Parameters in Grinding Ceramics, Annals of DAAAM for 2009 \& Proceedings of the 20th International DAAAM Symposium, 25-28th November 2009, Vienna, Austria, ISBN 978-3-901509-70-4, pp. 0361-0362, Published by DAAAM International Vienna, Vienna

Gutt, G.; Gutt, S.; Severin, T. - L. \& Vasilache, V. (2010). Research on the Spatial Distibution of Mechanical Characteristics in a Cadmium Telluride Crystal, Annals of DAAAM for 2010 \& Proceedings of the 21 st International DAAAM Symposium, 20-23rd October 2010, Zadar, Croatia, ISSN 1726-9679, ISBN 978-3-901509-73-5, Katalinic, B. (Ed.), pp. 0993-0994, Published by DAAAM International Vienna, Vienna

Manas, D.; Stanek, M.; Manas, M.; Pata V. \& Javorik, J. (2009). Influence of Mechanical Properties on Wear of Heavily Stressed Rubber Parts, KGK - Kautschuk Gummi Kunststoffe, 62. Jahrgang, , ISSN 0948-3276, p.240-245

Stanek, M.; Manas, M. \& Manas, D. (2009). Mold Cavity Roughness vs. Flow of Polymer, Novel Trends in Rheology III, AIP, ISSN 0094-243X, pp.75-85

Stanek, M.; Manas, M.; Manas, D. \& Sanda, S. (2009). Influence of Surface Roughness on Fluidity of Thermoplastics Materials, Chemicke listy, Volume 103, ISSN 0009-2770, p.91-95

Stanek, M.; Manas, M.; Manas, D. \& Sanda, S. (2009). Plastics Parts Design Supported by Reverse Engineering and Rapid Prototyping, Chemicke listy, Volume 103, ISSN 0009-2770, pp.91-95

Stanek, M.; Manas, M.; Drga, T. \& Manas, D. (2006) Polymer Fluidity Testing. 17th DAAAM, Vienna, Austria, p.395396, ISBN 3-901509-57-7

Stanek, M.; Manas, M.; Drga, T. \& Manas, D. (2006). Testing Injection Molds for Polymer Fluidity Evaluation, 17th DAAAM, Vienna, Austria, p.397-398,ISBN 3-901509-57-7

Stanek, M.; Manas, M.; Drga, T. \& Manas, D. (2006). ChipChunk Resistence of Tyre Treads, 17th DAAAM, Vienna, Austria, p.393-394, ISBN 3-901509-57-7 